\title{
Dez anos depois do boom dos diários digitais
}

\section{RESUMO}

Desde o boom dos diários digitais, há uma década, muita coisa sobre o jornalismo na rede mundial de computadores foi prenunciada por cientistas, profissionais da área ou aficionados pelo ciberespaço. Neste artigo, a idéia é resgatar depoimentos de jornalistas pioneiros que singram entre as turbulências e as calmarias do mercado da internet. A partir de suas perspectivas anunciadas logo depois da implantação dos jornais digitais, pretende-se verificar os prognósticos desses jornalistas em contraste com o estado da arte do jornalismo na web, suas transformações e pressupostos teóricos.

\section{PALAVRAS-CHAVE}

- jornalismo digital

- Internet

- jornalista

\section{ABSTRACT}

Since the boom of digital diaries, a decade ago, much about journalism in the world net of computers was foreseen by scientists, professionals in the area or cyberspace addicts. In this essay, the idea is to rescue testimonies by pioneer journalists who navigate amidst turbulence and calm of the internet market. Departing from their announced perspectives, soon after the implantation of digital newspapers, the objective here is to investigate their predictions in contrast with the state of art of journalism in the web, its changes and theoretical assumptions.

\section{KEY WORDS}

- digital journalism

- internet

- journalist

\section{Claudia Irene de Quadros UTP}

$\mathrm{H}$ á dez anos do boom do jornalismo digital, ainda que com objetivos distintos, empresários, jornalistas e pesquisadores da área da comunicação concentram esforços para tentar encontrar um modelo de diário que explore apropriadamente os recursos oferecidos pela Internet. Os avanços, desde o nascimento dos diários digitais na World Wide Web, são oriundos de iniciativas que vão de tímidas a ousadas, de reproduções de outros meios a novas soluções exclusivas para o ambiente em rede. No conjunto, essas ações fazem parte da evolução do jornalismo digital. Nesse processo, do ponto de vista antropológico, surgem novos elementos socioculturais, como novas técnicas, formas de organização de trabalho e conhecimentos. Esses elementos têm sido objetos de pesquisa dos mais diferentes campos da ciência. Por exemplo, nos estudos em jornalismo a preocupação em investigar o novo meio surge muito antes do boom dos diários na internet. $\mathrm{O}$ pioneirismo de pesquisadores em jornalismo digital hoje se revela em uma importante contribuição para o registro histórico do jornalismo praticado na rede mundial de computadores. À luz da era digital, esses pioneiros criam, resgatam e (re)discutem teorias da comunicação, além de buscar em outros campos do conhecimento alternativas para avançar em suas investigações. No artigo em tela, muitos desses estudos são recuperados ao lançar um olhar para o trabalho desenvolvido pelo jornalista pioneiro que continua a singrar entre as turbulências e as calmarias do mercado da Internet. Esses jornalistas, que já enfrentaram discriminações de seus colegas de profissão, ainda encontram na rotina de trabalho obstáculos econômicos, culturais e políticos. Complementam a metodologia desse estudo, a seleção de entrevistas semi-estruturadas realizadas por esta autora e de depoimentos de jornalistas pioneiros publicados em diversos veículos de comunicação nacionais e internacionais. Por meio de análises e cruzamento de dados históricos e atuais obtidos com os referidos instrumentos de pesquisa, a intenção é registrar as transformações da profissão com o impacto das tecnologias avançadas da comunicação.

Desde o boom dos diários digitais, muita coisa sobre o jornalismo na rede mundial de computadores foi prenunciada por cientistas, profissionais da área ou aficionados pelo ciberespaço. Nesse trabalho, a idéia é resgatar depoimentos de jornalistas pioneiros. A partir de suas perspectivas anunciadas logo depois da implantação dos jornais digitais, pretende-se verificar os prognósticos desses jornalistas em contraste com o estado da arte do jornalismo na web, suas transformações e pressupostos teóricos. Devido ao grande número de diários na World Wide 
Web, foi necessário fazer um recorte. Optou-se em selecionar depoimentos de profissionais de jornais brasileiros e espanhóis já analisados em pesquisas anteriores. $\mathrm{O}$ material coletado para essas pesquisas, e aqui publicado, é inédito, além de servir de referencial para dar partida nessa investigação. Compõem ainda a metodologia desse estudo, referências bibliográficas específicas do jornalismo digital. Muitas dessas pesquisas têm destacado a importância do jornalista na construção dos diários na World Wide Web. Vale destacar que cresce o número de cientistas preocupados em registrar e refletir as rotinas produtivas das redações digitais não apenas sobre o aspecto laboral, mas de sua função social.

\section{Da revolução à evolução}

Nesses dez anos do boom da implantação dos diários na Internet, o jornalismo na web não concluiu a sua fase de transição da esfera tradicional para a digital. É evidente que o esforço de pesquisadores, empresários e jornalistas em uma década pode ser observado em modelos de negócio, de narrativas, de gestão de conteúdos, de design, de processo informativo etc. que se configuram na rede mundial de computadores. No entanto, a evolução das tecnologias digitais da informação é muito mais rápida que a ação estratégica para implementá-las. Seja no Brasil, na Espanha ou em qualquer outro país é possível encontrar diários digitais em diferentes estágios, inclusive muitos deles ainda insistem em apenas reproduzir o conteúdo de suas versões impressas tal qual a estréia dos jornais na web num momento em que o mercado oferece sites que já exploram muitas das potencialidades proporcionadas pela hipermídia. No início, em meados dos anos 90, a disponibilização do conteúdo do jornal impresso na World Wide Web era uma espécie de vitrina para o mundo conectado (De Quadros, 1997). Mas as transformações estavam por vir, afinal, o processo de comunicação, usado pela mídia de massa, de um para todos (quando o emissor envia mensagens de um meio massivo para receptores passivos ) se diversifica de um para um, de um para muitos, de muitos para um, de muitos para muitos por meio do computador conectado à Internet. Era preciso planejar uma nova forma de fazer jornalismo na web para tirar proveito dessa mudança, das novas possibilidades de negócios, dos recursos hipermidiáticos e das expectativas do usuário. Muitos outros fatores influenciaram no momento de disponibilizar um diário na Internet, estudos de casos apontam que as circunstâncias particulares de cada empresa determinam o rumo que tomam os jornais digitais (De Quadros, 1999; Bastos, 2000; Saad, 2003; Torres, 2004; entre outros).

O jornalista, que optou em construir o novo meio, assumiu uma responsabilidade desafiadora: era sua função colocar em prática as grandiosas profecias dos gurus da internet, proporcionar a alardeada inter- atividade ao usuário e contribuir para o esperado lucro dos empresários. Tudo isso sem um plano definido. Saad (2003) recorda que as primeiras estratégias de muitos sites jornalísticos nem se importavam com o usuário. Mas não foi regra geral. Em 1998, o então editor da versão digital de "O Estado de São Paulo", Luiz Octavio Lima, enfatizava a sua preocupação com os avanços das tecnologias e a necessidade de estar em constante aperfeiçoamento. "Todos os dias novos recursos e novas verdades aparecem como definitivos e são derrubados a seguir. É preciso ter frieza para analisar o que é realmente importante e o que é modismo e vai passar logo". Para o jornalista era necessário deixar claro a função do jornalismo digital. "No fundo, é a mesma de sempre do jornalismo: levar informação ao usuário de forma mais bem empacotada possível, com a melhor qualidade e honestidade possível, utilizando ao máximo os recursos tecnológicos de que se dispõe" (Lima, 1998). Nas redações digitais, o surgimento de novas tecnologias não foi proporcional ao número de modelos que tentavam transformar o leitor em um usuário tão ativo como o percebido pela teoria. As primeiras e poucas tentativas nessa direção quase sempre ficaram limitadas ao e-mail, que se transformou em um poderoso instrumento eletrônico, mas nem sempre bem utilizado por razões técnicas ou de pessoal. Ainda hoje é comum verificar a inabilidade de algumas redações digitais no uso dessa ferramenta, que acaba sendo utilizada apenas como um adereço sem sentido. Dito de outro modo, o usuário envia a sua mensagem, mas recebe uma carta padrão que não se refere ao assunto tratado por ele no e-mail ou nem recebe um retorno.

Entretanto, os registros de tentativas pioneiras comprovam os esforços na busca da interação com o público. Nas versões digitais dos principais jornais brasileiros e espanhóis, a preocupação com o usuário sempre foi presente nas declarações de seus jornalistas. Num depoimento prestado no segundo semestre de 1997, Mariló Ruiz de Elvira, então responsável pelo diário El País Digital, destacava que uma das principais vantagens da Internet era "disponer de un abundante feedback de los lectores" (ELVIRA, 1997). Por isso, recomendava que a sua equipe conhecesse cada vez mais o perfil do usuário. Lucía Enguita Mayo, uma das editoras do El País Digital, recordava que a participação do usuário era importante para o processo de produção. "Recibimos más de 600 mensajes a la semana. Son usuarios que escriben para hacer una errata, un comentario o para participar de un debate. La verdad es que esta cooperación nos ayuda a producir un diario cada vez mejor" (Mayo, 1997). O correio eletrônico e outros benefícios advindos da internet, que propiciaram a (questionada) participação do leitor, denominado na era digital de usuário, foram considerados uma revolução para a história da comunicação. Nenhum outro meio oferecera tantas possibilidades de participação como a Internet. No entanto, logo no início, talvez pela falta 
de modelos e de pessoal treinado para explorar os recursos da hipermídia que possibilitavam a interatividade, foi apontada uma grande dicotomia entre a teoria e a prática. Nesse período, jornalistas como Luciano da Costa Martins, responsável pela chamada Net Estado, a versão digital de O Estado de São Paulo, criticavam prognósticos de teóricos: "Todo mundo fala que a interatividade é o máximo que se pode dar ao leitor na Internet. Isso é um mito. O máximo que se pode dar ainda é conteúdo de qualidade" (Martins, 1997).

Neste sentido, as grandiosas profecias dos teóricos do ciberespaço (Ferrari, 2003) feitas à luz da revolução digital não se cumpriram e acabaram por frustar muitos internautas. Não foi muito diferente o que aconteceu com empresários e jornalistas. Os primeiros, não tiveram tantos lucros como esperavam. Os segundos, os jornalistas das redações digitais, passaram por vários obstáculos. Entre eles, a necessidade de passar a ser um instantaneísta da notícia, ${ }^{1}$ a discriminação dos colegas das redações tradicionais por não entenderem a sua prática laboral como uma atividade do jornalismo, a demissão de jornalistas dos sites jornalísticos logo após a queda da bolsa de Nasdaq, o fechamento de diários recém lançados na web, redução de salários, a substituição de profissionais em jornalismo nas redações digitais por "produtores de conteúdo" sem formação na área e a fusão das redações tradicionais e digitais.

No aniversário de dez anos do boom do jornalismo na web, pode-se dizer que, entre erros e acertos, houve tempo para adquirir experiência, dominar um pouco mais a máquina e propor novos modelos de jornalismo com muito mais propriedade. Tanto no plano prático como no teórico, não se pode negar o passado em benefício de idéias e projetos inovadores. Nesse sentido, releituras de obras clássicas da comunicação, como as de McLuhan e Harold Innis, comprovam que a necessidade de verificar o passado é fundamental para a construção do presente. Dos debates sobre a revolução que deram lugar às abordagens reflexivas sobre a evolução do meio, surge uma esperança renovada de aproximar teoria e prática. A pesquisa aplicada é uma delas. Elias Machado propõe que os pesquisadores em jornalismo no Brasil "entrem em sintonia com as demandas sociais, desenvolvendo tecnologias específicas para o exercício da profissão nos mais variados suportes" (Machado, 2003: 42). As circunstâncias favorecem essa idéia. No campo da ciência da comunicação, um fenômeno, percebido nos últimos anos nas universidades espanholas e brasileiras, é o ingresso na pós-graduação de jornalistas, que trabalham ou já trabalharam em diários ou assessorias digitais, interessados em pesquisar com profundidade o jornalismo na web. Ao unir teoria e prática, eles têm contribuído para o desenvolvimento dessa área. Tal como afirmou Bourdieu, citado por Barros Filho e Martino (2003:25), “a diferença não está en- tre a ciência que opera uma construção e a ciência que não o faz, mas entre a ciência que o faz sem sabê-lo e a ciência que, sabendo-o, procura conhecer e dominar o máximo possível seus atos, inevitáveis, de construção e os efeitos que produzem também inevitavelmente". Do habitus ao campo, o jornalista pesquisador reavalia o seu trabalho e, em contato com a teoria, propõe novos modelos que favorecem o usuário. Esse fenômeno também beneficia o pesquisador que, mais próximo dos profissionais, toma contato, de forma contínua, com a realidade das redações digitais.

\section{Da experiência à renovaçáo}

Da experiência adquirida pelos jornalistas das redações digitais, dos empresários de comunicação e de pesquisadores surge também a esperança renovada de desenvolver sites jornalísticos que explorem adequadamente os recursos da hipermídia. Aqui serão destacados mais alguns depoimentos de jornalistas envolvidos com os diários digitais desde o seu nascimento. Muitas de suas declarações e ações da fase inicial do jornalismo na web ganharam valor de prognóstico para os campos profissional e científico. O jornalista e professor espanhol Mario Tascon afirmava, em 1997, que as transformações provocadas pela Internet obrigariam os demais meios a passar por adaptações. "La tecnología que utilizamos contagiará las redacciones tradicionales. Los departamentos de documentación serán el corazón de muchos nuevos servicios y los periodistas utilizarán con mucha frecuencia Internet como fuente documental" (Tascon, 1997). Mario Tascón ficou a frente do diário El Mundo del Siglo XXI desde a sua criação até setembro de 2000, quando foi chamado para coordenar as edições digitais do Grupo Prisacom, da qual fazem parte El País Digital, As e Cadena Ser. O El País Digital e o El Mundo del Siglo XXI são versões digitais do El Mundo e do El País, os dois diários mais vendidos na Espanha. A rivalidade desses dois jornais chegou aos tribunais com a saída de Mario Tascon. Pedrojota Ramírez, proprietário da Unidesa (editora do El Mundo) e Mundinteractivos, acusou o jornalista e o Grupo Prisa por concorrência desleal, apropriação de segredos empresariais, posse indevida de arquivos que ficaram vazios e pela contratação de mais da metade dos jornalistas que trabalhavam na redação do El Mundo del Siglo XXI. A sentença saiu em setembro de 2004, três anos depois. Tascón e Prisa foram absolvidos: “Los jueces desmontan todas las acusaciones y reconocen un comportamiento correcto y legal en la actuación desarrollada por los demandados" (El Pais, 21/09/ 2004). Os juízes ainda destacam no texto da sentença final o pioneirismo de Tascón no uso das tecnologias digitais e argumentam que o jornalista não poderia ter causado prejuízos ao El Mundo del Siglo XXI, pois as atividades do diário continuaram normalmente com o seu pedido de demissão. Tascón 
saiu do jornal, mas a sua marca permanece. A versão digital do El Mundo tornou-se uma referência por suas propostas inovadoras e foi escola para muitos jornalistas que ainda permanecem na sua redação. Por esse motivo, a sua saída também representou uma grande perda de capital humano. O processo de Pedrojota Ramírez contra Mario Tascón entra para a história do jornalismo web como uma tentativa de recuperar legalmente os possíveis prejuízos dessa perda. Afinal, o Grupo Prisa, ao contratar Tascón, sabia que não estava contratando apenas um jornalista especialista em Internet, mas reforçando o seu capital intelectual e, de modo consciente ou inconsciente, abalando a cultura organizacional do seu principal concorrente. $\mathrm{O}$ resultado da sentença final reforça que, na sociedade do conhecimento, as habilidades do homem se sobrepõe à tecnologia e são mais valorizadas. A ninguém pertence a sua capacidade de transformar conhecimentos subjetivos em ações. Isso não significa, no entanto, que o homem domina por completo a máquina.

A construção dos diários digitais na Espanha e no Brasil dependeu muito do esforço de jornalistas. Durante o percurso, desses dez anos de jornalismo na web, os seus profissionais adquiriram experiência, passaram a dominar algumas técnicas e apresentaram soluções inovadoras. A receita de sucesso para muitos deles não estava em dominar profundamente cada tecnologia que surgia. Luciano da Costa Martins, em 1997, afirmava que era fundamental "conhecer o sentido das tecnologias embarcadas na redação. Para planejar uma reportagem na web, escolher os aplicativos adequados e propor uma forma de leitura (links, cores, formato) é necessário um profundo conhecimento do leitor para avançar no jornalismo web" (Martins, 1997). No campo acadêmico, os rumos tomados pelas redações digitais nortearam estudos que hoje são referência. Da observação sistemática de diários digitais, o professor norte-americano John Pavlik (2001:110), afirma que a introdução das novas tecnologias não garante aumento de qualidade nos conteúdos das notícias e muito menos no desempenho dos jornalistas das redações digitais. Pavlik, um dos pioneiros da pesquisa em jornalismo digital, dá ênfase ao produto ao classificar os diários na www em três estágios. $\mathrm{O}$ primeiro é apenas a transposição do diário impresso para a web, o segundo apresenta o conteúdo da versão impressa e mais alguns produtos exclusivos da internet, e o terceiro um produto elaborado especificamente para o ciberespaço (Pavlik, 1997). Três meses antes do artigo publicado por Pavlik na Columbia Journalism Review, Mario Tascón descrevia na redação do El Mundo do Siglo XXI, em Madri, as fases já passadas pelos jornais digitais e as que ainda estariam por vir: "En la primeira volcamos los contenidos del periódico impreso en la versión digital. En la segunda volcamos los contenidos de la versión digital. En la tercera el producto ya se diferencia sensiblemente del periódico impreso. La cuarta fase todavía no la conocemos. Será el periódico del futuro" (Tascon, ago.1997).

Baseado nos estudos de Pavlik e de outros pesquisadores, o Grupo de Estudos em Jornalismo Online (GJOL), da Universidade Federal da Bahia, desenvolveu uma tipologia que ajuda a compreender o desenvolvimento dos sites jornalísticos. Nessa tipologia, os diários digitais são classificados em três fases: primeira geração ou fase de transposição, de segunda geração ou fase de metáfora e de terceira geração ou fase de exploração das características do suporte web (Mielnizuk, 2003). Nos estudos do projeto "Web Semântica", 2 de Tim Berners Lee, a evolução da www também é categorizada por fases denominadas de primeira, segunda ou terceira geração (YEE, 2001). Luciana Mielnizuk destaca que é possível encontrar em só diário digital aspectos de diversas fases propostas pelo grupo de pesquisa da UFBA. "Não se trata de uma divisão estanque no tempo e tais categorias também não são excludentes entre si" (Mielnizuk, 2003: 45). A tipologia desenvolvida pelo GJOL pode ser aplicada sob o ponto de vista do produto, da disseminação de informações ou da produção.

As pesquisas em jornalismo digital têm ampliado os seus focos de atenção para atender as demandas sociais. Marcos Palácios acredita que o conhecimento também avança com as tentativas de "compreender os modos de articulação e transformação das características dos múltiplos suportes existentes, dentre os quais o online, confrontando-os com as práticas que efetivamente têm lugar no cenário da produção jornalística" (Palácios, 2003:16). É importante destacar que descobertas científicas, em qualquer país, sofrem intervenção de muitos fatores. Castells, citado por Saad (2003: 25), destaca a criatividade e a iniciativa empreendedora. Por exemplo, muitos dos estudos desenvolvidos na Espanha refletem a realidade das redações digitais e o seu entorno. As primeiras teses sobre jornalismo digital defendidas na Espanha, no final da década de 90, tentam fazer um mapeamento de aspectos que preocupavam as equipes das redações digitais da época, como: interatividade, publicidade na internet, instantaneidade, mudança nas práticas laborais, ética, desenho web, banco de dados etc, propondo ou não alguns modelos para o jornalismo na rede mundial de computadores. Esse fenômeno pode ser verificado em vários países. Sebastião Squirra destacou, em 1998, as prioridades das redações digitais no momento do boom da Internet, como o valor dado aos bancos de dados.

Passado dez anos, esses e muitos outros aspectos fazem parte das inquietações de pesquisadores e profissionais. A diferença é que tanto profissionais como pesquisadores tiveram tempo de adquirir experiência e, por que não, de aprender um com o outro. O discurso do e pelo novo, impregnado de exaltação tecnológica, perdeu o sentido no presente. 
No entanto, os resultados adquiridos no passado (recente) dão sustentação para a evolução do jornalismo na web. Obras de referência para esse artigo e pesquisas em andamento comprovam o crescimento da área e o amadurecimento de modelos (não conclusivos) apresentados. mamecos

\section{NOTAS}

1 A expressão instantaneísta da notícia foi criada por Ignacio Ramonet. Jornalista, do francês journaliste, significa analista de um dia. Então, para Ramonet, os que trabalham em um diário digital devem ser chamados de instantaneístas, analistas do dia (Adghirni, 2002).

2 Informações sobre o projeto de Web Semântica, de Tim Bernes Lee podem ser obtidas no site http://www.w3.org/2001/sw/

\section{REFERÊNCIAS}

ADGHIRNI, Zélia Leal. Jornalismo on-line em busca do tempo real. In HOHFELTD, Antonio e BARBOSA, Marialva (orgs.). Jornalismo no século XXI: a cidadania, Porto Alegre, Mercado Aberto, 2002.

BASTOS, Helder. Jornalismo Electrónico. Internete Reconfiguração de práticas nas redações. Coimbra, Minerva, 2000.

BARROS FILHO, Clóvis de e MARTINO, Luis Mauro Sá. O habitus na comunicação, São Paulo, Paulus, 2003.

BAUER, Martin W. e GASKELL, George. Pesquisa qualitativa com texto, imagem e som. Um manual prático. $2^{\mathrm{a}}$ ed., Petrópolis, Editora Vozes, 2003.

DE QUADROS, Claudia Irene. El futuro del periodismo en internet, Bella Terra, IV Jornadas Internacionales de Jóvenes Investigadores en Comunicación, 1997.

DE QUADROS, Claudia Irene. Periodistas y diarios electrónicos: las exigencias profesionales en la Red. La Laguna, tese doutoral defendida na Espanha, 1999.

- Desestimada una demanda de El Mundo contra El País por competencia. Madrid, El Pais, 21/09/2004.

ELVIRA, Mariló Ruiz. Entrevista por e-mail concedida à Claudia Irene de Quadros, em out. de 1997.

FERRARI, Pollyana. Jornalismo Digital, São Paulo, Editora Contexto, 2003.
LIMA, Luiz Octavio. Entrevista concedida por email à Claudia Irene de Quadros, em mar. de 1998.

MACHADO, Elias. O ciberespaço como fonte para os jornalistas. Salvador, Calandra, 2003.

MAYO, Lucía Enguíta. Entrevista pessoal concedida à Claudia Irene de Quadros em Madri, em ago. de 1997.

MARTINS, Luis da Costa. Entrevista por e-mail concedida à Claudia Irene de Quadros em out. de 1997.

MIELNICZUK, Luciana. Sistematizando alguns conhecimento sobre jornalismo na web in MACHADO, Elias e PALÁCIOS, Marcos (orgs.) Modelos de Jornalismo Digital. Salvador, Calandra, 2004.

PALÁCIOS, Marcos. Ruptura, continuidade e potencialização no jornalismo on-line: o lugar da memória in MACHADO, Elias e PALÁCIOS, Marcos (orgs.) Modelos de Jornalismo Digital. Salvador, Calandra, 2004.

PAVLIK, John. The future of Journalism Online, Columbia Journalism Review, november 1997, pp 30-36, New York, Columbia University, 1997.

PAVLIK, John. Journalism and New Media. New York, Columbia University Press, 2001.

SAAD, Beth. Estratégias para a mídia digital. São Paulo, Editora Senac, 2003.

SQUIRRA, Sebastião. Jornalismo Online, São Paulo, Editora Arte \& Ciência, 1998.

TASCON, Mario. Entrevista por e-mail concedida à Claudia Irene de Quadros em out. de 1997.

TASCON, Mario. Entrevista pessoal concedida à Claudia Irene de Quadros em ago. de 1997.

TORRES, María Bella Palomo. El periodista on line: de la revolución a la evolución, Sevilla, CS, 2004.

YEE, Raymond. The sea change of the Web: What is the Second-Generation, Semantic Web?, IST Interactive University Berkeley Computing \& Communications, Vol. 11, N. 4, october 2001. 